\title{
An Integrated Business Core: Hindsight Evaluation And Recommendations
}

\author{
Norm Borin, (Email: nborin@calpoly.edu), California Polytechnic State University
}

\begin{abstract}
Over the last decade a number of business schools have developed integrated business programs. These programs have differed in a number of ways including the degree programs involved, the depth of the integration, and the pedagogy used to teach integrative concepts. Until recently there have been few studies published that have reported the effectiveness of these programs. A forthcoming study reports the results of an extensive analysis of a fully integrative business core program. The program has since been discontinued at this school. This paper provides a series of recommendations, based on the difficulties this school had with running and ultimately continuing their program.
\end{abstract}

\section{Introduction}

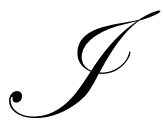

n response to a number of both internal and external forces many business schools during the 1990's and early 2000's developed integrative business programs at both the undergraduate and graduate level (e.g, Auckland University of Technology, University of Idaho, The University of Tennessee, Boston University, University of Pennsylvania, University of Tennessee, California Polytechnic San Luis Obispo). Although the motivation for their development has been well discussed (Watkins et al. 1998, Perotti et al. 1998, Porter, L.W., \& McKibbin, L.E. 1998, Barber et. al. 2001) in brief, many programs have arisen due to the rapidly changing business environment, input from corporate America, challenges from accrediting bodies and research on effective student learning pedagogies. These programs present a number of challenges to both faculty and students but there have been few studies that provide insights into the effectiveness of these programs. A recent article (Barber et. al. 2004 forthcoming) presents an empirical analysis of one colleges measurement of the effectiveness of their undergraduate business program. Since that time this college's program has been discontinued for a number of reasons. This article presents a summary of this college's experiences with their Integrated Core Program (ICP) and provides a list of hindsight recommendations for schools contemplating a program of their own.

\section{The Integrated Core Program}

The main objective of our college's ICP was to provide students with an understanding of how the various functional areas interrelate, in addition to facilitating learning of the various functional foundations and managerial concepts. Details of the program with illustrative examples of the curriculum design are presented in Barber et al. 2001. It is important to note that both the ICP and non-ICP options were simultaneously offered at the college. Students had the option of taking the business core classes either way - though they had to apply for admittance to the ICP option. The courses in the program represented the traditional functional business areas of accounting, economics, finance, management, management information systems and marketing, as well as a broader government, business and society course. The ICP was offered once a year for a three-year period. One section of ICP was offered the inaugural year, with two sections offered each of the subsequent two years (each section contained approximately 40 students).

Integrative education within the ICP was attempted in a number of ways. First, during many sessions multiple faculty representing different functional areas would be co-teaching in the classroom. For example, a case 
discussion would take place that discussed a company's pricing policy for a new product introduction. This case would have both an accounting and marketing professor present to discuss pricing using theories and concepts from their respective disciplines. Each day of the ICP was divided into both an integrative and a functional session. Second, throughout the six months students worked towards completion of a comprehensive business plan. During this period they were constantly exposed to content in the classroom that related to specific parts of the business plan. In-depth analysis of all functional areas was required for this project.

During the three years of the program there was an attempt to keep the same faculty involved in the ICP. Due to the steep learning curve, faculty did not truly understand the intricacies of the program until the middle of the second year. Yet despite these attempts there was a great deal of turnover for a number of reasons. First, the workload was intense and despite reduced teaching loads outside the ICP, many faculty suffered burnout. Second, faculty consistently had to make compromises as part of a team. This was very difficult for those who find the independent nature of academic life as one of its most attractive features. Third, the program was relatively controversial (this will be further discussed in the hindsight recommendations section). Many faculty decided the negative association with the program outweighed the positives.

\section{Measuring the Programs Effectiveness}

With the exception of Perotti et. al. 1998 and Hartenian et al. (2001), there have been few studies that have attempted to measure the effectiveness of an integrative program. In the Perotti et. al. study a student focus group was performed to evaluate strengths and weaknesses of the school's integrated program. Although this information was used to modify the program, there was not an extensive assessment and evaluation of program outcomes. Hartenian et al. 2001 study focused on an integrative course and used a number of measures including changes in learning and behavior.

Although a number of measures were gathered during our college's three year ICP no formal attempt to measure its effectiveness was done until after the program ended. (The program was very expensive and funding was not available to continue it. Many faculty involved in the program thought it would continue and were surprised when the decision was made to end it.) At this time a study was done that compared the ICP against nonICP students on a number of variables. Since both programs were being run at the same time the college was in a unique position to undertake this analysis without issues such as history effects taking place. Detailed descriptions of the measurement variables are presented in Barber et al. (2004) forthcoming and are summarized in Table 1.

Table 1 Variables Used to Evaluate the Effectiveness of the ICP

\begin{tabular}{|c|c|}
\hline Variable & Description \\
\hline Skills and Competencies & $\begin{array}{l}\text { An internally developed list of variables that represent } \\
\text { skills that the college felt all graduates should leave with a } \\
\text { strong level of achievement. One variable measured } \\
\text { understanding of interdisciplinary concepts. Survey was a } \\
\text { student self assessment. }\end{array}$ \\
\hline Managerial Competency Questionnaire & $\begin{array}{l}\text { An externally developed (Hay/McBer) standardized } \\
\text { questionnaire that measures skills found to be important } \\
\text { for effective managers. }\end{array}$ \\
\hline Functional Exam & $\begin{array}{l}\text { An internally developed standardized exam that measured } \\
\text { concepts from all functional areas taught within the ICP } \\
\text { and non-ICP }\end{array}$ \\
\hline Course Grades & $\begin{array}{l}\text { Each student at the college was required to take a } \\
\text { capstone business class that taught and evaluated cross- } \\
\text { functional knowledge and abilities. }\end{array}$ \\
\hline Student Satisfaction & $\begin{array}{l}\text { Student Satisfaction with the program was measured } \\
\text { throughout the three years. Exit interviews were also } \\
\text { done at the completion of the program. }\end{array}$ \\
\hline
\end{tabular}




\section{Results}

Although there were a large number of comparisons made between students in the ICP and non-ICP programs key measure of interest was integrative knowledge. One of the major objectives of most integrative business programs is to present a pedagogy that improves the students' ability to integrate concepts from multiple functions. Table 2 provides a comparison of the ICP and non-ICP students on this variable. ICP students both perceived and showed that they had internalized this concept better than non-ICP students.

Table 2 Comparison of ICP and non-ICP Students on Cross-Functional Knowledge

\begin{tabular}{|l|c|c|c|}
\hline Measure & \multicolumn{2}{|c|}{ Means } & Significance \\
\hline Self-reported internally developed survey. $^{1}$ & Non-ICP & 5.36 & .00 \\
\hline Externally Developed Managerial Competency $^{1}$ & ICP & 5.90 & .04 \\
Questionnaire (self reported) $^{2}$ & Non-ICP & .63 & .69 \\
\hline Cross Functional Cross-Functional Exam $^{3}$ & ICP & $50 \%$ & .003 \\
\hline Business Policy Class Grade $^{4}$ & Non-ICP & $55 \%$ & .02 \\
& ICP & 3.2 & 3.6 \\
\hline
\end{tabular}

1 Means represent the average score on variables that had loadings of greater than .5 on a factor. Scale is 1 to 7 with $1=$ not at all, $4=$ to some extent and $7=$ to the highest extent.

2 Scores are percentages and represent the frequency these behaviors were demonstrated

3 Score is percentage based on a 100 point exam.

4 Grade is based on a 4 point scale

Although ICP students did better on other variables such as communication and critical thinking skills the differences were not significant. Interestingly, the non-ICP students viewed themselves as much more culturally aware than the ICP students. This is perhaps due to the fact that ICP students spend so much time with there own group and are not exposed to as large a number of other students relative to non-ICP students.

\section{Hindsight Recommendations}

Despite the promising results of the ICP, and the fact that so many environmental factors support the concept, our program ended after its third year. Although a lack of funding was cited as the main reason, there were a number of issues that unless resolved would have made continuation problematic. Hindsight now allows us to make specific recommendations for those colleges that are considering integrative programs. These suggestions center on those issues that created the most problems during our three years. (A comprehensive discussion of general recommendations for integrative programs can be found in Aurand (2001) and Pharr (2000).)

Get your financial house in order! These programs are usually quite expensive. Our college received initial funds to run the program for three years. The cost of our program was estimated at approximately $\$ 250,000$ incrementally over the existing non-integrative core. These funds were used primarily for faculty release time. Because of the intense workload of the program faculty were essentially given two classes release time over a two-quarter timespan. Despite the president's and business advisory council's verbal support the college's attempt to obtain additional funds to keep the program going were unsuccessful. Although a larger fund base would be ideal we would recommend a reevaluation of the structure of the program (see below). The faculty involved considered options such as shortening the program to one quarter. In this scenario there would be less time devoted to functional areas and more time to integrative concepts.

Get advanced faculty and other stakeholder buy-in. Although most of the faculty involved in our program were committed to its success, most of the other non-participating faculty at the college were either neutral or negatively predisposed towards it. There was not an extensive amount of discussions at the college level prior to the programs start-up. Most faculty were vaguely aware of the program but were never updated on its progress. Additional 
parties that should be consulted would include administration, students, employers and advisory councils (Pharr 200). We suggest:

Hold pre-start up meetings. Make sure all faculty are aware of the program and how it will be run, how it will affect them and how it improves the students learning experience. Getting faculty input during the development stage will assist the college in obtaining some level of ownership from all faculty. Given the large resource requirement faculty buy-in is critical.

Mission Fit. Demonstrate how the program fits with the college's mission and strategic plan. Many faculty not involved in the ICP wondered why we were doing it and had either or neutral or negative impression of it. If we had clearly communicated to faculty how the ICP fit with the college's mission and helped move the college forward there would clearly have been more support.

Provide adequate compensation. Because of additional meetings and preparation ours and most ICP programs add to the work-load of faculty already putting in full weeks. Although in our program there was some release time allocated it was viewed as inadequate. Either more release time is needed, particularly in the first year of involvement, or some other form of compensation needs to be made. Like many universities today, we have an annual review and reward process but participating in the ICP was not given any special consideration. Faculty research productivity is definitely impacted and unless this issue is also given consideration it can be difficult to recruit faculty, particularly untenured faculty, into these types of programs.

Multi-year commitment. We found that those faculty who knew they would only be involved in the ICP for one year were less committed to the program. This would manifest itself in a variety of ways. For example, these faculty were often more resistant to teaching in the integrative sessions and preferred to spend more time in their own functional time slots. Many of these faculty did not provide significant feedback on the cross-functional business plans students did. If faculty know they will be in the program for more than one time period there may be a stronger level of involvement in the integrative parts.

Provide periodic updates. The coordinator of the ICP should hold periodic forums to give quick updates to non-ICP faculty. This will reduce the levels of mistrust that is often created - particularly when some view additional compensation with envy. Ongoing learning objective measurements can be presented at these forums that will provide empirical evidence of the programs effectiveness.

Talk to the students. We did an excellent job of getting feedback from the students. Three times a quarter we asked for their evaluation of the program and used their input to fine-tune issues. Most of the input was related to logistical issues e.g, not enough time for break-out sessions, but it definitely made the students feel they were an integral part of the program. One issue that was particularly sensitive to the students was grading. We spent a great deal of time as a faculty team evaluating and deciding on the final grades. In our ICP program the students received one grade each quarter. However, this grade was applied to 12 units ( 24 total) of college credit. Thus, a C would have a significant impact on the overall g.p.a. With this in mind we were more lenient with grades than many of us would be if a student were in a non-ICP course.

Develop Objectives in advance. Although we had some general idea that we wanted to develop integrative skills and knowledge in the program we never really defined what this meant or how it was to be measured. Throughout the program different measures were done such as student self-rating of integrative skills and faculty assessment of how well they felt integration was being achieved. After the program was ended a few faculty did a post-hoc study using some admittedly imperfect measures. It is our recommendation that clear concise learning objectives be established for the program and measures be developed that will determine whether these objectives are met. Admittedly, integrative knowledge is a challenging concept (many of our measures probably measured cross functional knowledge more than integrative knowledge) and we thus recommend that multiple measures of this concept be developed. Clear objectives will also assist in the development of the program. For example, if leadership skills are identified as key learning objectives then pedagogical tools need to be incorporated which focus on these skills. 
Avoid multiple program types. Since our program was experimental, it was only available to a limited number of students. As stated earlier, the non-ICP took place concurrently. This created many moments of tension when students from both programs communicated and compared notes on such things as workload, faculty, grading and scheduling. It is our recommendation that all students participate in the eventual program. This would require a significant buy-in from the student body. This should not be too difficult if the program is viewed as a distinctive advantage of the college. One recommendation would be too involve students in the program development. Our ICP students were quite outspoken about the time scheduling of the classes which were quite rigid. This is one case where feedback from them early on could have helped reduce dissatisfaction later.

Consider smaller steps. Integrated programs can be implemented in many different formats from a few classes or projects to extensive programs such as that described for our school. Schools lacking significant resources or with a degree of faculty skepticism should consider reduced levels of integration. For example, since our school dropped the program we are adding integrative components such as an integrative industrial sales course, and an entrepreneurship program. Any school considering integrative programs should thoroughly review program alternatives at other schools. A number of articles describing these programs have recently been appearing in academic journals (Aurund 2001).

\section{Summary}

Presented here is a series of recommendations for schools that are considering the development of an integrative program. The recommendations are based on the personal experiences of a college that developed and operated an undergraduate business integrative core program for three years. After a three year period the program was ended due to funding limitations. Beyond increased funding, recommendations are made to ensure that the faculty buy-in to the program and that the program has well established objectives and measures. Although the effort required to successfully run an integrated program is great, the benefits to both faculty and students can be well worth it. Almost all faculty and student participants at this school felt it was a worthwhile learning experience. Although at the current time, resource constraints prevent a program of this type to be reproduced, the overwhelming benefits of the program have led many faculty to discuss alternative less expensive formats of an integrated nature.

\section{References}

1. Aurand, Timothy W., Carol DeMoranville and Geoffrey L. Gordon (2001), "Cross-functional business programs: Critical Design and development considerations." Mid - American Journal of Business. 16, 2 21-31.

2. Barber, Clifford, Borin, Norm, Cerf, Doug C. and Swartz, Teresa A. (2001) "The Role of Marketing in an Integrative Business Curriculum," Journal of Marketing Education, (23) 240-248.

3. Barber, Clifford, Borin, Norm, Cerf, Doug C. and Swartz, Teresa A. "An Approach to Measuring the Effectiveness of Innovative Business Programs," Journal of the Academy of Business Education, forthcoming.

4. Hartenian, Linda S, Schellenger, Michael and Paul Frederickson. (2001) "Creation and Assessment of an integrated business course: One college's experience.” Journal of Education for Business. (76, 3) 149160.

5. Hay/McBer Training Resources Group. Managerial Competency Questionnaire. Boston, MA (1997).

6. Pharr, Steven W. (2000) "Foundational considerations for establishing an integrated business common core curriculum," Journal of Education for Business $(76,1)$ 20-24.

7. Perotti, Valerie S., Gunn, Patricia C., Day, John C. and Coombs, Garth. (1998) "Business 20/20: Ohio University's Integrated Business Core," Educational Innovation in Economics and Business III, R.G. Milter eds. Kluwer Academic Publishers, Netherlands. 169-188.

8. Porter, L.W., \& McKibbin, L.E. (1998). Management education and development: Drift or thrust into the $21^{\text {st }}$ century. New York: McGraw Hill.

9. Watkins, Todd A., Ochs, John B., Boothe, Berrisford W. and Beam Heather. (1998) "Learning Across Functional Silos," Educational Innovation in Economics and Business III, R.G. Milter eds. Kluwer Academic Publishers, Netherlands. 147-167. 
Notes 